\title{
Functional conservation between rodents and chicken of regulatory sequences driving skeletal muscle gene expression in transgenic chickens
}

\author{
Michael J McGrew*, Adrian Sherman, Simon G Lillico, Lorna Taylor, Helen Sang
}

\begin{abstract}
Background: Regulatory elements that control expression of specific genes during development have been shown in many cases to contain functionally-conserved modules that can be transferred between species and direct gene expression in a comparable developmental pattern. An example of such a module has been identified at the rat myosin light chain (MLC) 1/3 locus, which has been well characterised in transgenic mouse studies. This locus contains two promoters encoding two alternatively spliced isoforms of alkali myosin light chain. These promoters are differentially regulated during development through the activity of two enhancer elements. The MLC3 promoter alone has been shown to confer expression of a reporter gene in skeletal and cardiac muscle in transgenic mice and the addition of the downstream MLC enhancer increased expression levels in skeletal muscle. We asked whether this regulatory module, sufficient for striated muscle gene expression in the mouse, would drive expression in similar domains in the chicken.

Results: We have observed that a conserved downstream MLC enhancer is present in the chicken MLC locus. We found that the rat $M L C 1 / 3$ regulatory elements were transcriptionally active in chick skeletal muscle primary cultures. We observed that a single copy lentiviral insert containing this regulatory cassette was able to drive expression of a lacZ reporter gene in the fast-fibres of skeletal muscle in chicken in three independent transgenic chicken lines in a pattern similar to the endogenous MLC locus. Reporter gene expression in cardiac muscle tissues was not observed for any of these lines.

Conclusions: From these results we conclude that skeletal expression from this regulatory module is conserved in a genomic context between rodents and chickens. This transgenic module will be useful in future investigations of muscle development in avian species.
\end{abstract}

\section{Background}

The development of an organism entails the precise expression of lineage and tissue-specific gene products in a temporally-regulated manner during embryogenesis. The information for a cell to respond to external signals by differentiating down a particular developmental pathway is 'hardwired' into the regulatory regions surrounding these developmentally regulated genes [reviewed in [1]]. These conserved regulatory regions or modules drive spatial gene expression patterns in the forming tissues of the developing organism. Changes in the cis-regulatory elements of regulatory modules are hypothesized

\footnotetext{
* Correspondence: mike.mcgrew@bbsrc.ac.uk

The Roslin Institute and Royal Dick School of Veterinary Studies, University of Edinburgh, Roslin, Midlothian, UK
}

(c) 2010 McGrew et al; licensee BioMed Central Ltd. This is an Open Access article distributed under the terms of the Creative Commons Attribution License (http://creativecommons.org/licenses/by/2.0), which permits unrestricted use, distribution, and reproduction in any medium, provided the original work is properly cited. to be the predominant mechanism behind evolutionary changes in pattern formation [2].

Many expression modules have been shown to be functionally conserved in vertebrate species. For example, regulatory regions from several hox genes from fish and chicken are capable of driving some aspects of the spatial expression patterns of the paralogous murine gene in transgenic mice [3-6]. Examples of conserved regulatory modules have been shown for the processes of neurogenesis [7-9], limb morphogenesis [10] and haematopoiesis [11,12], amongst many other examples.

We, and others, have previously shown that lentiviral vectors can be used to generate transgenic chickens and that cis-regulatory regions incorporated into these vectors will drive ubiquitous or tissue-specific expression in 
this species [13-16]. In this report we investigate the possibility of utilising rodent regulatory elements to drive transgene expression in skeletal muscle of chickens. To achieve this we investigated the transcriptional activity of the rat $M L C$ regulatory domains in transgenic chickens. This locus encodes two alkali myosin light chains expressed from two promoters that are differentially regulated during development. The MLC1 isoform is expressed at embryonic stages of development and in the fast fibres of skeletal muscles of the adult. The MLC3 isoform is expressed at fetal stages and in the atria of the mouse heart $[17,18]$. The construct we used consists of the rat $M L C 3$ promoter, which is transcriptionally active in all striated muscle in mouse transgenic models $[18,19]$, and a downstream rat $M L C$ enhancer which augments skeletal muscle expression and confers expression at embryonic stages of development [20,21]. We show that a putative $M L C$ enhancer is present in the chicken $M L C$ locus. Using the rat $M L C$ regulatory elements, we show that these elements support transgene expression in skeletal muscle of chickens. Cardiac transgene expression was not detected. These results indicate a functional conservation of the $M L C$ regulatory elements exist between rodents and chickens in the skeletal muscle lineage. This demonstration is significant not only for the use of the chicken as a model organism for studies in developmental biology but also because poultry are an economically important food source.

\section{Results and Discussion}

The mammalian $M L C$ locus consists of two widely separated promoters driving expression of two protein isoforms of the alkali MLC and a downstream enhancer [20,22-24]. The exon structure of the chicken, rat, mouse, and human myosin light chain $1 / 3$ locus is highly conserved [22-26]. (Fig. 1top). The rat and mouse $M L C$ enhancer and the $M L C 1$ promoters were previously shown to drive robust expression in fast skeletal muscle of transgenic mice [20,21]. Cardiac expression was shown to be dependant on the $M L C 3$ promoter $[18,19]$.

Examination of the chicken locus at an analogous position for the $M L C$ enhancer enabled us to identify a region of homology shared with human, rat, mouse, and opossum (Fig. 1bottom). A closer examination of this region revealed a putative enhancer module containing regulatory elements that closely resemble the core myosin light chain enhancer as defined in mouse, rat and human $[19,27,28]$. This core enhancer contains three canonical E boxes (CANNTG) that bind to the myogenic factors, myf-5, MRF4, myoD, and myogenin and an $\mathrm{A} / \mathrm{T}$ rich region containing a sequence matching the consensus binding site of MEF2 [27]. All four regulatory motifs are present in this DNA sequence as indicated in
Fig. 1. These data suggest that the structure of the $M L C 1 / 3$ locus is highly conserved between mammals and chicken.

\section{Generation of a muscle-specific reporter cassette}

To define a regulatory module that is sufficient for gene expression in the striated muscle of transgenic chickens, we used the regulatory regions from the rat $M L C 1 / 3$ locus to drive expression of a lac $Z$ reporter gene. These elements were both introduced upstream of the $l a c Z$ reporter gene in a minimal EIAV replication-defective lentiviral vector to create the construct pONY-MLZ (Fig. 1C). To test the transcriptional activity of the lentiviral construct in chicken cells, transient transfections of the construct were carried out into primary cultures of embryonic chicken cardiac and skeletal muscle cells and the transfected cells were stained for $\beta$-galactosidase activity (Fig. 2). An upstream CMVenhancer/promoter regulatory region used for packaging the lentiviral construct was first removed from this plasmid to avoid possible transactivation of the downstream $M L C 3$ promoter (see Methods). A GFP reporter construct was co-transfected to visualise transfection efficiency into these cells (Fig. 2A, 2B). Transfections into skeletal muscle primary cultures demonstrated that long myotubular cells stained positive for $\beta$-galactosidase whilst surrounding fibroblasts did not (Fig. 2B'). In transfections into cardiac muscle primary cultures, no expression of $\beta$-galactosidase was detected (Fig. 2A'). These results indicate that the $M L C$ regulatory module is transcriptionally active in skeletal muscle cells but is not active in cardiac muscle. We went on to test this module in vivo using transgenesis.

\section{Generation of transgenic chickens carrying the MLC-lacZ transgene}

To generate transgenic chickens containing a MLC transgene, a concentrated preparation of pONY-MLZ replication-defective lentivirus was produced. The virus was injected into the sub-germinal cavity of fertilised eggs at the new-laid egg stage. Injected eggs were incubated until hatching using the surrogate shell culture system as described [13]. A total of 12 chickens were hatched and all were identified as transgenic for the EIAV vector by semi-quantitative PCR of DNA from blood samples. One cockerel, estimated to have an incidence of $10 \%$ transgene integration in the germline by PCR analysis of semen DNA, was bred with stock hens and $G_{1}$ transgenic offspring identified. Seven $G_{1}$ offspring were produced and genomic DNA from these birds analyzed by restriction enzyme digestion and Southern blot analysis to determine the number of vector insertions in each bird and the number of different insertion events represented in the $G_{1}$ generation. 


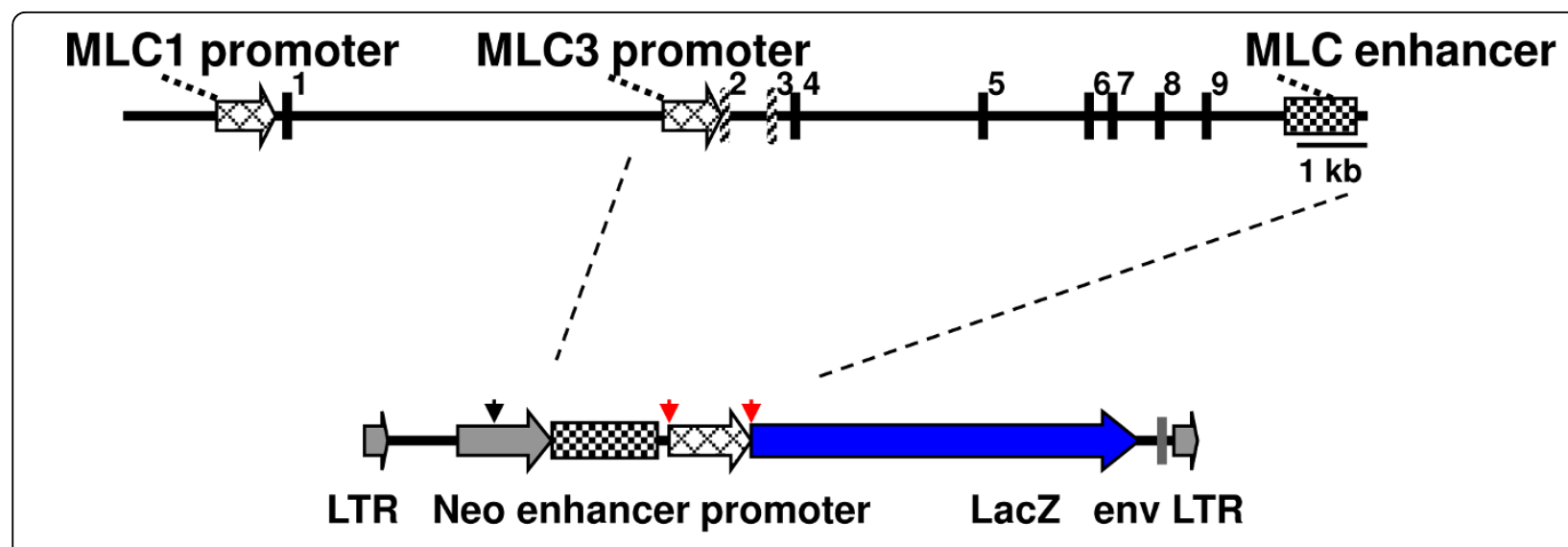

CHICKEN CTTGGCCCCATCTGCCAGCATGCAGGAGATTTTTTTGGGGAAGCCTTGCAAAA RAT TAAATTACCATGTGTGAACCGCTCATAA---------------CTCAAGTC MOUSE TAAATTACCATGTGTGAAGCGTCCATAA---------------CTCAAGTA

HUMAN TAAATTACCATGTGTGAAATGCCTGTAA--------------CTCAAGTA

OPOSSUM TAAATTACTGGGTCTGAAATAGC CTCAAGCA

\section{Site $A$}

CHICKEN

RAT

MOUSE

HUMAN

OPOSSUM

CHICKEN

RAT

MOUSE

HUMAN

OPOSSUM

CHICKEN

RAT

MOUSE

HUMAN

OPOSSUM GAGGCAGCTGCTGCTCCACTGGCTGTGCTGTGGCTTATTCT----------GCAGCAGGTGCAAAAATGGAGCTGCGCAGGCAGAAGAGTGATCGTCATTTTTA ACAGCAGGTGCAAAAATGGAGCTGCAGGCAGAAGAGTGGT--AGTCATTTTTA ACAGCAGGTGCAAAATAAAGTAGCAGGCGGAAGAGTGACAGT----AATTTTT ATAGCAGGTGCATCCGAGAGGAAGGGTTGGGACACTGATGAT----AATTTTT

\section{Site B Site C} -----CATGCCAGCTGCCC-CTGGTGCACCTGTTGGTGCTTGAATGATGGAG AAATC-CCCACCAGCTGGCG-AAGCAACAGGTGCCTAАTTCCTCAT-----CAAATCCCCACCAGCTGGCG-AAACAACAGGTGCCTAATTCCTCAG------AАСАTCTACACCAGCTGGCAAAAATGACAGGTGCCTAATTCCTCAG------AACATCGACACCAGCTGGAGCAAATGACAGGTGCTAGGTTTCCAAA-------

\section{MEF-2} CTTGTTCTGCGCTGTAACTTAATAAGGCAAAGTCAgATTTTAATAGAACAAAC

Figure 1 The rat $M L C 1 / 3$ locus and lentiviral construct. Top: The rat $M L C$ locus consists of two separate promoter elements which generate two alternatively spliced transcripts. A downstream enhancer augments expression from both promoters in skeletal muscle. Stippled exons are specific for MLC3. The internal MLC3 promoter and the downstream enhancer were cloned upstream of a lacZ reporter construct in an EIAV replication defective lentiviral vector to generate pONY-MLZ. Restriction sites for HindllI (red arrows) and Sph1 (black arrows) are indicated. Bottom: Sequence comparison of homologous downstream regions of the MLC1/3 locus of eutherans and chickens. Grey boxes highlight core enhancer elements identified in human, mouse, and rat. The internal basepairs of the $E$ box of Site $A$ are changed to the sequence of site $B$ in the chicken. Site $C$ is in reverse orientation in the chicken to that in mammals. 

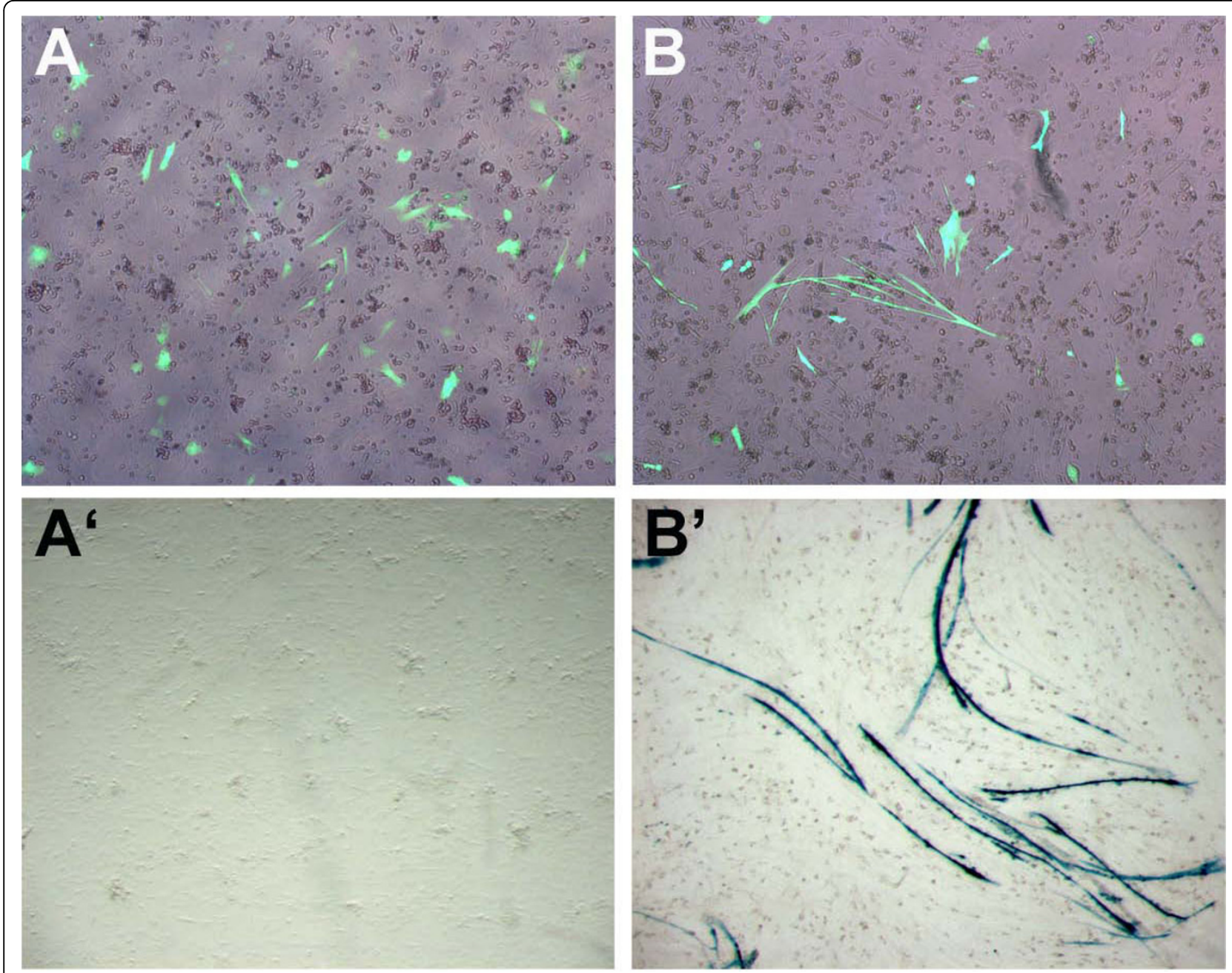

Figure $\mathbf{2} M L C 3$ regulatory elements are transcriptionally active in chicken skeletal muscle but not cardiac muscle primary cultures Cardiac $\left(A, A^{\prime}\right)$ and skeletal $\left(B, B^{\prime}\right)$ muscle chick primary cultures were co-transfected with the MLC3 lentiviral construct and a CAG-GFP reporter construct. Three independent experiments were carried out and a representative field is shown. A, B: GFP fluorescence $A^{\prime} B^{\prime}$ : X-gal staining of primary cultures. Large myotubes are stained in B'.

Genomic DNA digested with HindIII and Sph1 generated junction fragments that revealed that all seven birds contained single vector insertions and four independent insertions were present in the $\mathrm{G}_{1}$ birds (Fig. 3). Four $\mathrm{G}_{1}$ birds, each carrying a different transgene integrant, were bred to generate $G_{2}$ birds which were analysed in the subsequent experiments.

\section{Transgene expression is limited to avian skeletal muscle}

To determine the transcriptional profile of the $M L C$ expression module in transgenic chickens, selected tissues from chickens carrying each of the four independent vector insertions were assayed for $\beta$-galactosidase protein by ELISA (Fig. 4 , top). $\beta$-galactosidase protein was detected in breast and leg muscle of three transgenic lines (lines 2, 18, 75). The skeletal muscle expression levels were relatively robust. For example in line
$75,0.25 \%$ of the total protein in skeletal muscle was $\beta$ galactosidase. Non-muscle tissues did not contain $\beta$ galactosidase. No $\beta$-galactosidase was detected in tissue samples from the fourth transgenic line (line 76). It is possible that the integrated vector for this line has acquired a mutation that inactivated the transgene or that it has integrated into a transcriptionally silent site.

Unexpectedly, no $\beta$-galactosidase was detected in heart atria or ventricles of birds from any of the three expressing lines. In transgenic mice, the $M L C 3$ promoter alone drove $\beta$-galactosidase expression in cardiac muscle of transgenic mice (3 of 3 mouse lines) [18]. Addition of the $M L C$ enhancer to the transgene construct inhibited expression in cardiac tissues of two out of three transgenic mouse lines. A similar effect was also reported by Zammit et al., [21]. The lack of expression in cardiac tissue from the transgenic chickens 


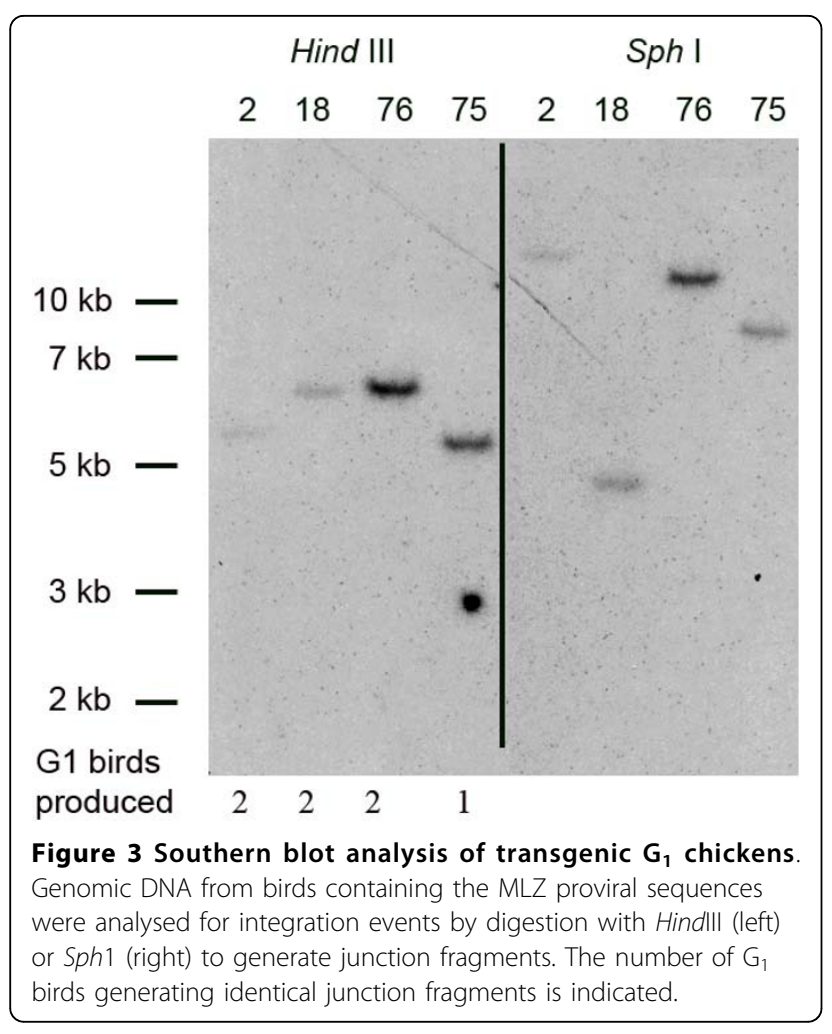

mimicked the result obtained by transfection experiments into chicken cardiomyocytes and was also similar to the expression patterns observed in transgenic mice for constructs containing the $M L C$ enhancer.

Tissues from the transgenic adult birds were stained for $\beta$-galactosidase activity to observe the spatial expression pattern in skeletal muscle. Non-muscle tissues and cardiac muscle did not stain for $\beta$-galactosidase (Fig. 4, bottom). Pectoral muscle of the breast was entirely stained for $\beta$-galactosidase. Immunofluorescence of chicken pectoral muscle with an antibody to chicken myosin light chain 1 and 3 revealed extensive expression throughout this tissue (Fig. 4C). In contrast to the pectoral musculature, staining of leg muscle displayed a cobbled expression pattern. Chicken pectoral muscle contains predominantly fast fibre muscle (white muscle) whereas leg musculature contains both fast and slow muscle fibres (red muscle) $[29,30]$. This result suggests that the transgene is expressed extensively in the fast fibre tissue of the breast flight muscle and is restricted in expression in leg muscle which contains slow as well as fast muscle fibres.

Tissue from the leg muscle was stained for $\beta$-galactosidase and an adjacent section immunostained with fast and slow fibre-specific antibodies [31], to demonstrate that the transgene expression is limited to fast fibres. The results shown in Fig. 5A and 5B demonstrate that the fibres that stained for $\beta$-galactosidase activity were also labelled with the fast fibre marker, F59. Conversely, fibres negative for $\beta$-galactosidase activity were immuno-positive for the slow fibre marker, S58. This finding is in accordance with results obtained in mouse models, which demonstrated that the $M L C 1 / 3$ regulatory module conferred expression to fast muscle fibres $[18,19,32]$.

To demonstrate that the transgene expression follows that of the endogenous $M L C 1 / 3$ locus, a tissue section was stained for $\beta$-galactosidase and an adjacent section immunostained with an antibody to MLC1 and 3 isoforms (F310) (Fig. 5C, 5D) [33]. Muscle fibres that are negative for $\beta$-galactosidase activity are immuno-negative for MLC1 and 3 indicating that the rat regulatory elements are expressed in a similar fibre type as the endogenous gene.

\section{The $M L C$ module drives early embryonic expression}

We next examined the temporal expression pattern of the MLC construct at selected embryonic stages and compared these expression patterns with those of the endogenous locus, to determine if the transgenic construct is accurately developmentally regulated. Staining of chicken embryos for $\beta$-galactosidase activity revealed that the MLC transgene was expressed in the forming myotome of day 3 (HH stage 19) chicken embryos (Fig. 6A-6C). In situ hybridisation with a riboprobe specific for $M L C 1$ and 3 mRNA also revealed that the endogenous chicken locus is transcribed in the chicken myotome at this stage (Fig. 6D). Abundant staining of the cardiac tube was also apparent. An analysis of later stages revealed extensive staining of $\beta$-galactosidase activity through the forming muscle masses of day 10 (midincubation) transgenic chicken embryos (Fig. 6E, 6F). These analyses show that the MLC regulatory module is sufficient to drive embryonic expression in skeletal muscles of chicken but not in cardiac tissue. Transgenic constructs containing these regulatory elements had previously been shown to be expressed in the myotome of developing transgenic mouse embryos $[18,19,21]$. Thus, our results indicate a conservation of temporal expression patterns between rodents and chicken.

\section{Conclusion}

These experiments are a further demonstration that the chicken can be used as an alternative model for transgenic analysis of gene regulation and of the use of lentivirus in avian transgenesis. These results indicate that the MLC regulatory module is functionally conserved for fast muscle fibre expression in mammals and birds and is developmentally regulated. Regulatory regions in the MLC enhancer are also conserved between mammals and chicken (Fig. 1). In contrast, sequences in the $M L C 3$ promoter are divergent when compared to the 


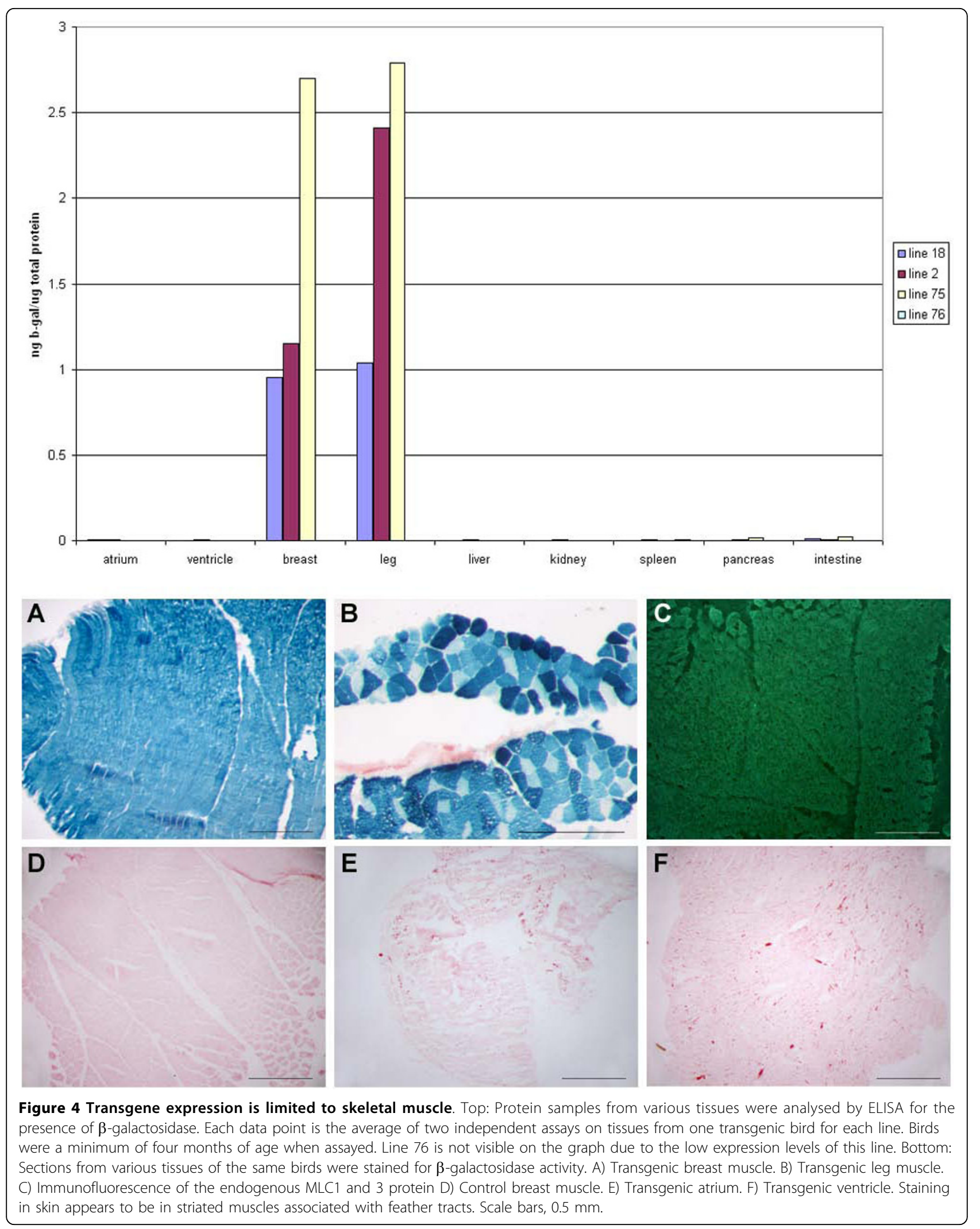



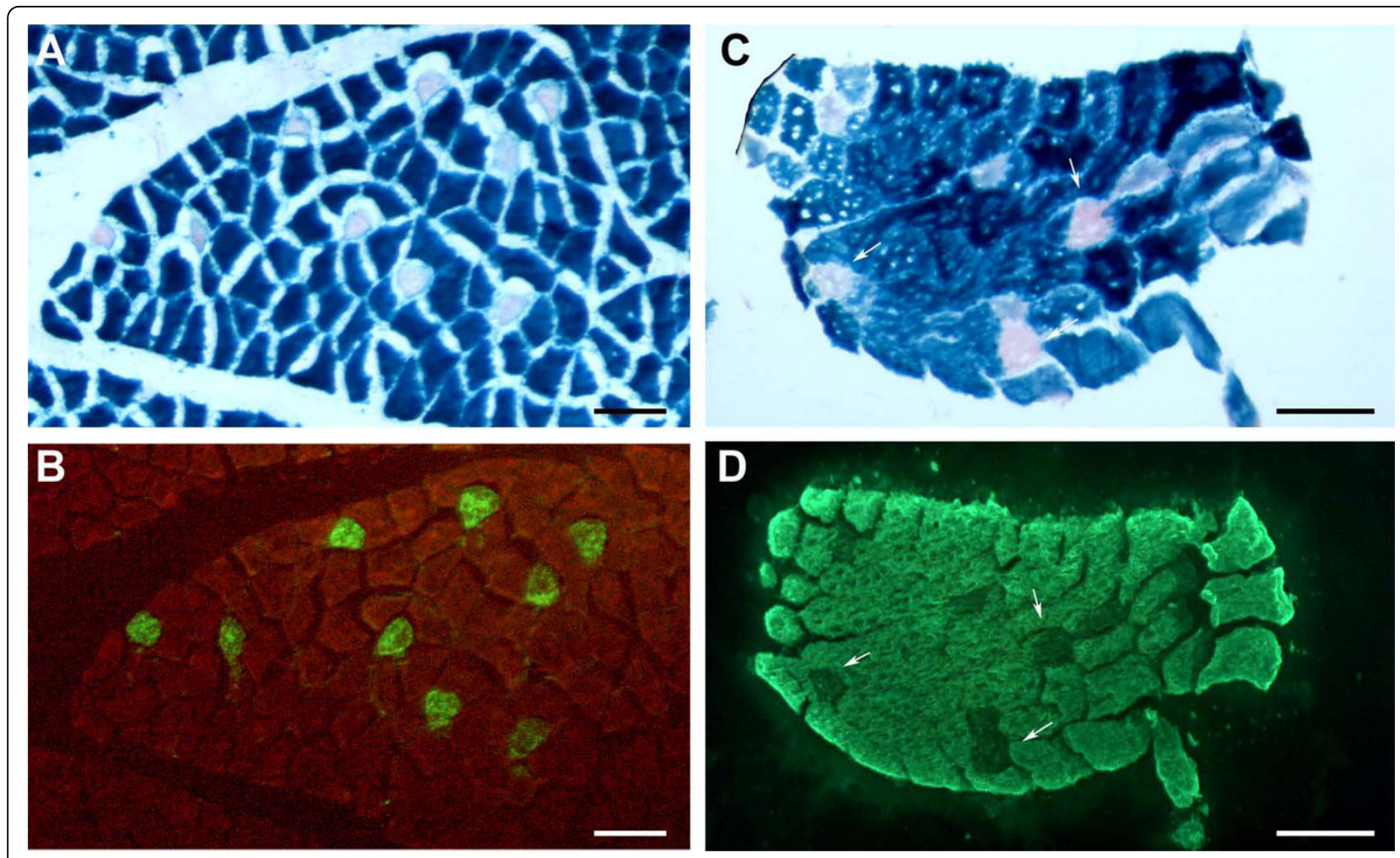

Figure 5 Transgene expression is restricted to fast skeletal muscle fibres and is expressed in a similar fibre type as the endogenous locus. A) A section from an interior leg muscle of a transgenic chicken was stained for $\beta$-galactosidase activity. The animal was at least four months old when assayed. B) A serial section to the one above was immuno-stained for fast (red) and slow (green) muscle isoforms. Fibres that are negative for $\beta$-galactosidase are labelled with an antibody to slow muscle. C) A section from an interior leg muscle of a second line of transgenic chicken was stained for $\beta$-galactosidase activity. D) A serial section to the one above was immuno-stained for MLC1 and 3 muscle isoforms (green). Fibres that are negative for $\beta$-galactosidase do not express MLC1 and 3. White arrows indicate corresponding myofibres. Scale bars, $0.1 \mathrm{~mm}$.

$M L C 1$ promoter $[18,25]$. The GATA regulatory element of the rat $M L C 3$ promoter, essential for cardiac expression in the rat, is not conserved in the chicken MLC3 promoter, yet there is expression from the endogenous $M L C 1 / 3$ locus in the embryonic chicken heart (Fig. 6D), suggesting that regulatory modules for avian cardiac expression are divergent from those in mammals.

The construct described here will be useful as an expression module to drive skeletal muscle expression in avian species. This will have applications for the expression of proteins or RNAs in avian muscle tissue for studies of muscle differentiation and function. For example, the expression of microRNAs targeting genes involved in skeletal muscle myopathy in broiler chickens could be specifically targeted to skeletal muscle using this regulatory module [34]. Additionally, similarly constructed transgenes will permit the analysis of candidate genes, identified by QTL mapping and expression analyses, implicated in control of muscle mass in chicken lines selected for increased muscle mass [35,36]. Inherent difficulties still remain in the generation of transgenic chickens including the long period to sexual maturity (16 weeks) and the difficulties in generating high titre lentivirus for large and complex transgenes.

\section{Methods}

Lentivirus construction and packaging

The 628 bp MLC3 promoter was isolated from p628Luc920 [18] using HindIII and subcloned into the HindIII site of the minimal EIAV lentiviral vector pONY8.45NCmcs [15]. A lacZ reporter gene was isolated from pONY 8.45NCZ using Sph1 and Xho1 and subcloned into the $X h o 1$ and Nru1 sites of the above plasmid to generate pONY8.45NCMLC3-Z. A residual $\mathrm{CMV}$ promoter was deleted from this vector by digestion with EcoR1 and SacII and re-ligation of the plasmid. Finally, a 920 bp MLC enhancer fragment was isolated from p628Luc920 [18] using BamH1 and subcloned into the Not 1 site upstream of the introduced promoter fragment to generate pONY8.45N-E-MLC3-Z (pONY-MLZ). The original direction of the enhancer was reversed in this construct. Packaged virus stocks 

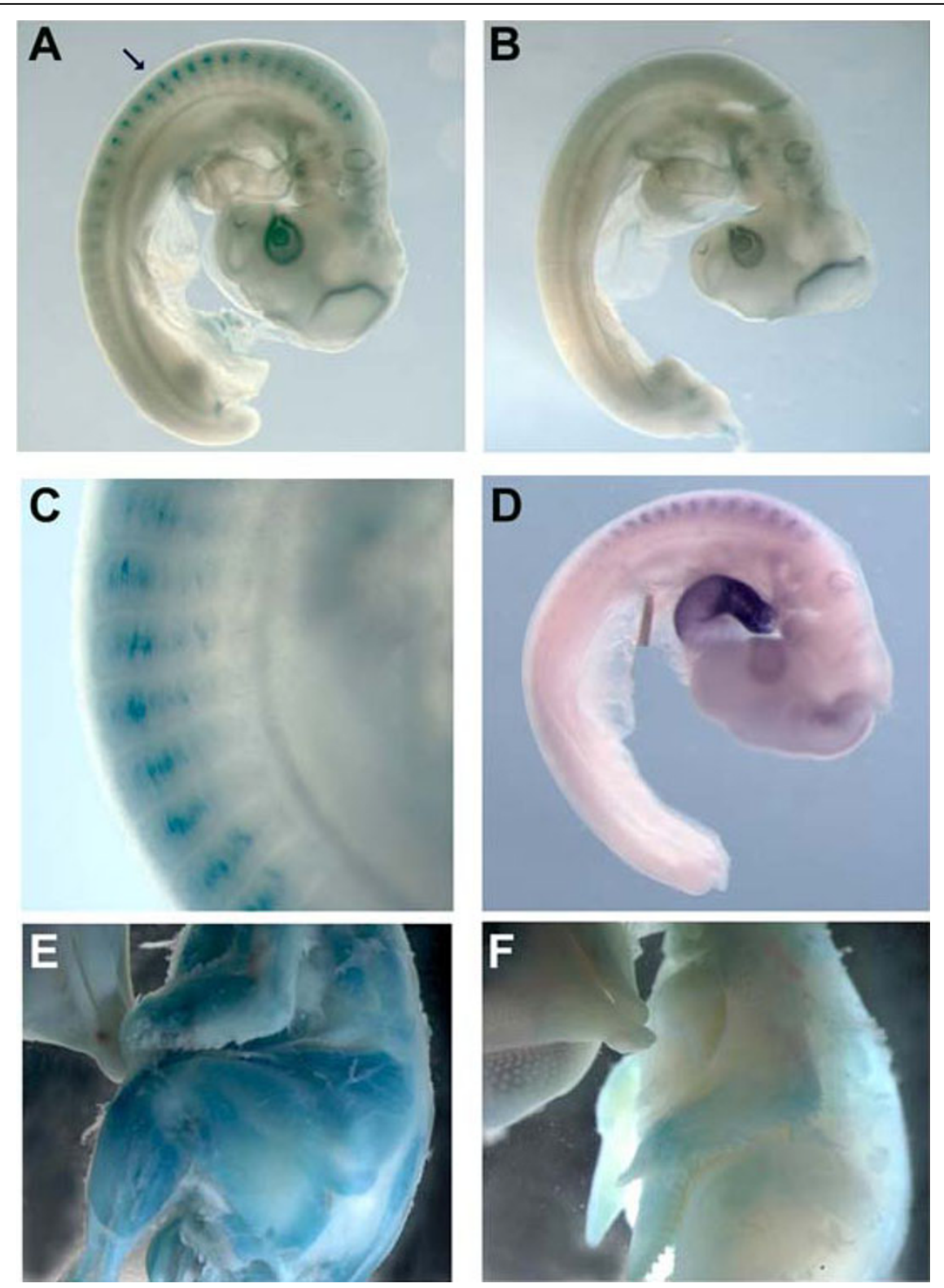

Figure 6 Transgene expression in the forming chicken embryo. Transgenic and control embryos were stained for of $\beta$-galactosidase activity. A) Transgenic and (B) control embryos at day 3 of development. C) Higher magnification of the embryo in (A) to show staining in the forming myotome. D) Transcripts from the endogenous locus at day 3 are revealed by in situ hybridisation for both MLC1 and 3. E) Transgenic and (F) control embryos at day 10 of development. Arrow, myotome.

were generated by FuGENE6 (Roche, Lewes, U.K.) transfection of HEK $293 \mathrm{~T}$ cells plated on $10 \mathrm{~cm}$ dishes with 2 $\mu \mathrm{g}$ of vector plasmid, $2 \mu \mathrm{g}$ of $\mathrm{gag} / \mathrm{pol}$ plasmid (pONY3.1) and $1 \mu \mathrm{g}$ of VSV-G plasmid (pRV67) [37]. 36-48 hours after transfection supernatants were filtered $(0.22 \mu \mathrm{m})$ and stored at $-80^{\circ} \mathrm{C}$. Concentrated viral preparations were made by initial low speed centrifugation at $6,000 \times \mathrm{g}$ for 16 hours at $4^{\circ} \mathrm{C}$ followed by ultracentrifugation at $50,500 \times \mathrm{g}$ for 90 minutes at $4^{\circ} \mathrm{C}$. The virus was resuspended in formulation buffer ( $20 \mathrm{mM}$ Tris,
$100 \mathrm{mM} \mathrm{NaCl}, 10 \mathrm{mg} / \mathrm{ml}$ sucrose, $10 \mathrm{mg} / \mathrm{ml}$ mannitol, $\mathrm{pH}$ 7.4) for $2-4$ hours, aliquoted and stored at $-80^{\circ} \mathrm{C}$. Viral titre was estimated at $4.5 \times 10^{7}$ T.U./ $/$ l.

\section{Production and analysis of transgenic birds}

Founder transgenic birds were generated by injection of viral particles into fertilised eggs at the new-laid egg stage, followed by culture of the embryos to hatch as described $[13,38]$. The hatched chicks were raised to; sexual maturity and DNA extracted from semen from 
adult males was screened by PCR (13) to; identify cockerels that carried vector sequences in the germ line. One cockerel identified by this method was crossed to; stock hens and their offspring screened by PCR to; identify $\mathrm{G}_{1}$ hemizygous transgenic birds. All experiments, animal breeding, and care procedures were carried out under license from the U.K. Home Office.

The vector insertions in individual $\mathrm{G}_{1}$ birds were analyzed by Southern transfer. Genomic DNA $(10 \mu \mathrm{g})$, extracted from whole blood, was digested with HindIII or $\operatorname{Sph} 1$ restriction endonucleases, resolved on a $0.7 \%$ agarose gel, and transferred to Hybond- $\mathrm{N}$ membrane (Amersham Biosciences, U.K.). These blots were analyzed by using a probe of the lac $\mathrm{Z}$ coding sequence, labelled with $\left[{ }^{32} \mathrm{P}\right] \mathrm{dCTP}$ using a RediPrime II kit (Amersham Biosciences). Hybridization was in $500 \mathrm{mM}$ sodium phosphate ( $\mathrm{pH} 7.2) / 7 \% \mathrm{SDS}$ at $65^{\circ} \mathrm{C}$ and signal was detected by autoradiography.

\section{Transfection of chicken primary cultures}

The lentiviral plasmids described above were digested with $B g l \mathrm{II}$ and $\mathrm{Xba}$ I and re-ligated to remove a $1.8 \mathrm{~kb}$ CMV enhancer/promoter fragment used for transcribing the lentiviral constructs during packaging and which could potentially transactivate the downstream $M L C 3$ promoter (pONY-MLZ-del CMV constructs).

Skeletal or cardiac tissue was isolated from day 9 chicken embryos, macerated and dissociated in trypsin for $3 \times 5$ minutes with vigorous pipetting. The solution was spun at $1000 \times \mathrm{g}, 5$ minutes, and re-suspended in plating media $(10 \% \mathrm{FBS}, 1 \%$ chick serum in DMEM, $1 \times$ NEAA). On day two of culture, cells were transfected using Fugene HD (Roche) with 5 ug of pONY-MLZ (del CMV) constructs and 1 ug of CAG-GFP in $35 \mathrm{~mm}$ tissue culture plates (Primaria, BD Biosciences). Culture media for skeletal muscle cultures was changed to differentiation media ( $2 \%$ chick serum in DMEM, $1 \times$ NEAA) after 24 hours. All plates were incubated for two additional days, photographed for GFP fluorescence, and stained for $\beta$-galactosidase activity as described below.

\section{Analysis of $\beta$-galactosidase activity and processing of tissues}

Selected tissues were snap-frozen and total protein extracted by homogenization in PBS containing protease inhibitors (complete mini, Roche). Protein concentration was determined by Bradford assay. ELISA was performed using $\beta$-gal Elisa kit (Roche). Elisa assays were carried out on two $G_{1}$ birds for each integration event. The data shown in Fig. 4 are for one transgenic animal for each integration event.

Adult tissues were isolated, fixed for $30 \mathrm{~min}$ in $4 \%$ paraformaldehyde, $0.25 \%$ gluteraldehyde in phosphate buffered saline (PBS) and tissues cryo-embedded and sectioned at $14 \mu \mathrm{m} . \beta$-galactosidase activity was detected by incubating at $37^{\circ} \mathrm{C}$ in $5 \mathrm{mM}$ potassium ferricyanide, $5 \mathrm{mM}$ potassium ferrocyanide, $2 \mathrm{mM} \mathrm{MgCl} 2,0.5 \mathrm{mg} / \mathrm{ml}$ $\mathrm{X}$-gal for 90 minutes, counterstained with eosin and mounted. Fast (F59) and slow (S58) fibre-type antibodies and an antibody against MLC1 and 3 isoforms (F310), developed by F.E. Stockdale, were obtained from the Developmental Studies Hybridoma Bank, University of Iowa, and used at 1:10 dilutions. The secondary antibodies used were TRITC conjugated goat anti-mouse IgG and FITC conjugated goat anti-mouse IgA (Sigma), and Alexa Fluoro 488 conjugated goat anti-mouse IgG respectively. Slides were counterstained with Hoechst, and mounted with Vectashield mounting media (Vector). Whole mount in situ hybridizations were carried out as described [39]. The riboprobe to MLC1 and 3 transcripts was described in [18].

\section{Acknowledgements}

We are grateful to K. Mitrophanous and L. Elliot for valuable input on the project and to N. Rosenthal for providing the MLC regulatory module. We thank H. Gilhooley, M. Hutchison, R. Mitchell and F. Thomson for care of transgenic birds and processing of samples. This work was supported by the Biotechnology and Biological Sciences Research Council, U.K. and by Viragen Inc.

\section{Authors' contributions}

MJM and HS conceived and designed the experiments. SGL produced and titred the virus. AS produced the transgenic birds. LT cloned several of the plasmid constructs. MJM performed most of the analysis. MJM wrote the manuscript with subsequent contributions from all authors. All authors read and approved the final manuscript.

Received: 7 August 2009

Accepted: 25 February 2010 Published: 25 February 2010

\section{References}

1. Istrail S, De-Leon SB, Davidson EH: The regulatory genome and the computer. Dev Biol 2007, 310:187-195.

2. Carroll SB: Evo-devo and an expanding evolutionary synthesis: a genetic theory of morphological evolution. Cell 2008, 134:25-36.

3. Gérard M, Duboule D, Zákány J: Structure and activity of regulatory elements involved in the activation of the Hoxd-11 gene during late gastrulation. EMBO J 1993, 12:3539-3550.

4. Morrison A, Chaudhuri C, Ariza-McNaughton L, Muchamore I, Kuroiwa A, Krumlauf R: Comparative analysis of chicken Hoxb-4 regulation in transgenic mice. Mech Dev 1995, 53:47-59.

5. Beckers J, Gérard M, Duboule D: Transgenic analysis of a potential Hoxd11 limb regulatory element present in tetrapods and fish. Dev Biol 1996 180:543-553.

6. Papenbrock T, Peterson RL, Lee RS, Hsu T, Kuroiwa A, Awgulewitsch A: Murine Hoxc-9 gene contains a structurally and functionally conserved enhancer. Dev Dyn 1998, 212:540-547.

7. Bumaschny VF, de Souza FS, López Leal RA, Santangelo AM, Baetscher M, Levi DH, Low MJ, Rubinstein M: Transcriptional regulation of pituitary POMC is conserved at the vertebrate extremes despite great promoter sequence divergence. Mol Endocrinol 2007, 21:2738-2749.

8. Antonellis A, Huynh JL, Lee-Lin SQ, Vinton RM, Renaud G, Loftus SK, Elliot G, Wolfsberg TG, Green ED, McCallion AS, Pavan WJ: Identification of neural crest and glial enhancers at the mouse Sox 10 locus through transgenesis in zebrafish. PLoS Genet 2008, 4:e1000174.

9. Suster ML, Kania A, Liao M, Asakawa K, Charron F, Kawakami K, Drapeau P. A novel conserved evx1 enhancer links spinal interneuron morphology and cis-regulation from fish to mammals. Dev Biol 2009, 325:422-433. 
10. Sumoy L, Wang CK, Lichtler AC, Pierro LJ, Kosher RA, Upholt WB: Identification of a spatially specific enhancer element in the chicken Msx-2 gene that regulates its expression in the apical ectodermal ridge of the developing limb buds of transgenic mice. Dev Biol 1995, 170:230-242.

11. Bonifer C, Vidal M, Grosveld F, Sippel AE: Tissue specific and position independent expression of the complete gene domain for chicken lysozyme in transgenic mice. EMBO J 1990, 9:2843-2848.

12. Mason MM, Lee $E$, Westphal H, Reitman M: Expression of the chicken beta-globin gene cluster in mice: correct developmental expression and distributed control. Mol Cell Biol 1995, 15:407-414.

13. McGrew MJ, Sherman AS, Ellard FM, Lillico SG, Gilhooley HJ, Mitrophanous KA, Kingsman AJ, Sang H: Efficient production of germline transgenic chickens using lentiviral vectors. EMBO Rep 2004, 5:728-733.

14. Chapman SC, Lawson A, Macarthur WC, Wiese RJ, Loechel RH, BurgosTrinidad M, Wakefield JK, Ramabhadran R, Mauch TJ, Schoenwolf GC: Ubiquitous GFP expression in transgenic chickens using a lentiviral vector. Development 2005, 132:935-940.

15. Lillico SG, Sherman A, McGrew MJ, Robertson CD, Smith J, Haslam C, Barnard P, Radcliffe PA, Mitrophanous KA, Elliot EA, Sang HM: Oviductspecific expression of two therapeutic proteins in transgenic hens. Proc Natl Acad Sci USA 2007, 104:1771-1776.

16. McGrew MJ, Sherman A, Lillico SG, Ellard FM, Radcliffe PA, Gilhooley HJ, Mitrophanous KA, Cambray N, Wilson V, Sang H: Localised axial progenitor cell populations in the avian tail bud are not committed to a posterior Hox identity. Development 2008, 135:2289-2299.

17. Cox RD, Buckingham ME: Actin and myosin genes are transcriptionally regulated during mouse skeletal muscle development. Dev Biol 1992, 149:228-234

18. McGrew MJ, Bogdanova N, Hasegawa K, Hughes SH, Kitsis RN, Rosenthal N: Distinct gene expression patterns in skeletal and cardiac muscle are dependent on common regulatory sequences in the MLC1/3 locus. $\mathrm{Mol}$ Cell Biol 1996, 16:4524-4434.

19. Kelly R, Alonso S, Tajbakhsh S, Cossu G, Buckingham M: Myosin light chain $3 F$ regulatory sequences confer regionalized cardiac and skeletal muscle expression in transgenic mice. J Cell Biol 1995, 129:383-396.

20. Rosenthal N, Kornhauser JM, Donoghue M, Rosen KM, Merlie JP: Myosin light chain enhancer activates muscle-specific, developmentally regulated gene expression in transgenic mice. Proc Natl Acad Sci USA 1989, 86:7780-7784.

21. Zammit PS, Cohen A, Buckingham ME, Kelly RG: Integration of embryonic and fetal skeletal myogenic programs at the myosin light chain $1 \mathrm{f} / 3 \mathrm{f}$ locus. Dev Biol 2008, 313:420-333.

22. Nabeshima Y, Fujii-Kuriyama M, Muramatsu M, Ogata K: Alternative transcription and two modes of splicing results in two myosin light chains from one gene. Nature 1984, 308:333-338.

23. Periasamy M, Strehler EE, Garfinkel LI, Gubits RM, Ruiz-Opazo N, NadalGinard B: Fast skeletal muscle myosin light chains 1 and 3 are produced from a single gene by a combined process of differential RNA transcription and splicing. J Biol Chem 1984, 259:13595-13604.

24. Robert B, Daubas P, Akimenko MA, Cohen A, Garner I, Guenet JL, Buckingham $M$ : A single locus in the mouse encodes both myosin light chains 1 and 3, a second locus corresponds to a related pseudogene. Cell 1984, 39:129-140.

25. Strehler EE, Periasamy M, Strehler-Page MA, Nadal-Ginard B: Myosin lightchain 1 and 3 gene has two structurally distinct and differentially regulated promoters evolving at different rates. Mol Cell Biol 1985, 5:3168-3182.

26. Seidel $\mathrm{U}$, Arnold $\mathrm{HH}$ : Identification of the functional promoter regions in the human gene encoding the myosin alkali light chains MLC1 and MLC3 of fast skeletal muscle. J Biol Chem 1989, 264:16109-16117.

27. Donoghue M, Ernst H, Wentworth B, Nadal-Ginard B, Rosenthal N: A muscle-specific enhancer is located at the $3^{\prime}$ end of the myosin lightchain 1/3 gene locus. Genes Dev 1988, 2:1779-1790.

28. Rosenthal N, Berglund EB, Wentworth BM, Donoghue M, Winter B, Bober E, Braun T, Arnold $\mathrm{HH}$ : A highly conserved enhancer downstream of the human MLC1/3 locus is a target for multiple myogenic determination factors. Nucleic Acids Res 1990, 18:6239-6246.

29. Remignon H, Gardahaut MF, Marche G, Ricard FH: Selection for rapid growth increases the number and the size of muscle fibres without changing their typing in chickens. J Muscle Res Cell Motil 1995, 16:95-102.
30. Elminowska-Wenda G: Structure of skeletal muscles in leghorn type chicken from conservative and parent flocks. Folia Biol (Krakow) 2007, 55:147-152.

31. Miller JB, Crow MT, Stockdale FE: Slow and fast myosin heavy chain content defines three types of myotubes in early muscle cell cultures. J Cell Biol 1985, 101:1643-1650.

32. Neville C, Gonzales D, Houghton L, McGrew MJ, Rosenthal N: Modular elements of the MLC $1 \mathrm{f} / 3 \mathrm{f}$ locus confer fiber-specific transcription regulation in transgenic mice. Dev Genet 1996, 19:157-162.

33. Crow MT, Olson PS, Stockdale FE: Myosin light-chain expression during avian muscle development. J Cell Biol 1983, 96:736-744.

34. Sandercock DA, Mitchell MA: Myopathy in broiler chickens: a role for $\mathrm{Ca}(2$ +)-activated phospholipase A2?. Poult Sci 2003, 82:1307-1312.

35. Terčič D, Holcman A, Dovč P, Morrice DR, Burt DW, Hocking PM, Horvat S: Identification of chromosomal regions associated with growth and carcass traits in an $\mathrm{F}$ full sib intercross line originating from a cross of chicken lines divergently selected on body weight. Animal Genet 2009, 40:743-748.

36. Zheng Q, Zhang Y, Chen Y, Yang N, Wang XJ, Zhu D: Systematic identification of genes involved in divergent skeletal muscle growth rates of broiler and layer chickens. BMC Genomics 2009, 10:87.

37. Rohll JB, Mitrophanous KA, Martin-Rendon E, Ellard FM, Radcliffe PA, Mazarakis ND, Kingsman SM: Design, production, safety, evaluation and clinical applications of nonprimate lentiviral vectors. Methods Enzymol 2002, 346:466-500

38. Perry MM: A complete culture system for the chick embryo. Nature 1988, 331:70-72.

39. Henrique D, Adam J, Myat A, Chitnis A, Lewis J, Ish-Horowicz D: Expression of a Delta homologue in prospective neurons in the chick. Nature 1995, 375:787-790.

doi:10.1186/1471-213X-10-26

Cite this article as: McGrew et al:: Functional conservation between rodents and chicken of regulatory sequences driving skeletal muscle gene expression in transgenic chickens. BMC Developmental Biology 2010 $10: 26$.

\section{Submit your next manuscript to BioMed Central and take full advantage of:}

- Convenient online submission

- Thorough peer review

- No space constraints or color figure charges

- Immediate publication on acceptance

- Inclusion in PubMed, CAS, Scopus and Google Scholar

- Research which is freely available for redistribution

Submit your manuscript at www.biomedcentral.com/submit
Biomed Central 